\title{
Surgical resection of lung cancer in England: more operations but no trials to test their effectiveness
}

We appreciate the interest of the Leicester team and their co-authors. ${ }^{1}{ }^{2}$ Their contributions to thoracic surgical service provision are internationally recognised. We agree with them that when variation in clinical practice is discovered, it merits critical examination. The discovery of variation provides the impetus to resolve the uncertainty that often underlies it. When there is good evidence for the effectiveness of surgery in particular patient groups, we can take an evidence based stance on which patients are being disadvantaged by variation in practice, but in the absence of evidence we should not assume that more care is better care. ${ }^{3}$

We used radical mastectomy for breast cancer as an example. An RCT published in $1981^{4}$ added critical weight to a consensus developing during the 1970 s. $^{5}$ The findings of the RCT explicitly allowed the harm of surgery to be reduced without compromising effectiveness. Evidence based practice confined the role of surgery in breast cancer to control of the primary tumour and it became the principle that lesser operations were preferable. It was not that mastectomy 'evolved' to be a more effective operation as Lau and colleagues imply; radical mastectomy was simply abandoned. There are parallels to be drawn with lung cancer. The rationale for radical mastectomy, the benefit of which was refuted by RCT evidence, was to extend the reach of the operation in the pursuit of involved nodes. It would help if the boundary beyond which lung cancer surgery is unavailing were better defined and then the least damaging operation that achieves its objective could be universally recommended.

There was no devilment intended in our comments. We simply want to promote the cause of the 'fair test' as a means to gain unbiased evidence. ${ }^{6}{ }^{7}$ David Waller, a founder and lead surgeon in the MARS (Mesothelioma and Radical Surgery) trial, knows well that recruitment into trials is not easy but MARS has allowed cancer teams to advise people with mesothelioma, on the basis of evidence, that extrapleural pneumonectomy is not in their best interest. ${ }^{8}$ In Britain at least this evidence eradicated the variation in mesothelioma practice that went before. For lung cancer we have no such 
RCT evidence to define the extent of disease that is amenable to cure, or of the extent of surgery beyond which there is no additional benefit.

Only when we have evidence can we make clear recommendations as to what should be done in the best interests of patients and so reduce variation. Our editorial which headlined the need for trials to test effectiveness of lung cancer surgery $^{8}$ should be viewed as complementing the work published in Thorax on variation in lung cancer resection rates 910 Rather than counterpoint in the sense of contesting a proposition, we prefer the original meaning of the word: the setting of two melodies in conjunction with one another to create a harmonious effect.

Tom Treasure, ${ }^{1}$ Christopher Russell, ${ }^{2}$ Dion Morton, ${ }^{3}$ Fergus Macbeth, ${ }^{4}$ Martin Utley ${ }^{1}$

${ }^{1}$ Clinical Operational Research Unit, University College London, London, UK

${ }^{2}$ Department of Surgery, UCL, London, UK

${ }^{3}$ Academic Department of Surgery, University of Birmingham, Birmingham, UK

${ }^{4}$ National Institute for Health and Clinical Excellence, London, UK

Correspondence to Professor Tom Treasure, Clinical Operational Research Unit, University College London, London WC1, UK; tom.treasure@gmail.com

Contributors All authors have contributed to the thinking behind this response and have agreed this version.

Competing interests None.

Provenance and peer review Not commissioned; internally peer reviewed.

To cite Treasure T, Russell C, Morton D, et al. Thorax 2013;68:187-188.

Received 17 October 2012

Accepted 19 October 2012

Published Online First 10 November 2012

\section{CSLinked}

- http://dx.doi.org/10.1136/thoraxjnl-2012-202752

Thorax 2013;68:187-188.

doi:10.1136/thoraxjnl-2012-202880

\section{REFERENCES}

1 Lau KKW, Waller DA, Rathinam S, et al. Lung cancer resection rate is related to survival. Thorax 2013;68:187.

2 Russell RCG, Treasure T. Counting the cost of cancer surgery for advanced and metastatic disease. $\mathrm{Br} J$ Surg 2012;99:449-50.

3 Veronesi U, Saccozzi R, Del Vecchio M, et al. Comparing radical mastectomy with quadrantectomy, axillary dissection, and radiotherapy in patients with small cancers of the breast. $N$ Engl J Med 1981;305:6-11.

4 Ellis $\mathrm{H}$. If I had... If my wife had cancer of the breast. Br Med J 1978;1:896-7.

5 Evans I, Thornton H, Chalmers I, et al. Testing treatments. 2nd edn. London: Pinter \& Martin, 2011.
6 Treasure T, Morton D. GRIST: Growing Recruitment in Interventional and Surgical Trials. J $R$ Soc Med 2012;105:140-1.

7 Treasure T, Lang-Lazdunski L, Waller D, et al. Extra-pleural pneumonectomy versus no extra-pleural pneumonectomy for patients with malignant pleural mesothelioma: clinical outcomes of the

Mesothelioma and Radical Surgery (MARS) randomised feasibility study. Lancet Oncol 2011:12:763-72.

8 Treasure T, Russell C, Morton D, et al. Surgical resection of lung cancer England: more operations but no trials to test their effectiveness. Thorax 2012;67:759-61.

9 Rich AL, Tata LJ, Free CM, et al. Inequalities in outcomes for non-small cell lung cancer: the influence of clinical characteristics and features of the local lung cancer service. Thorax 2011;66:1078-84.

10 Riaz SP, Linklater KM, Page R, et al. Recent trends in resection rates among non-small cell lung cancer patients in England. Thorax 2012;67:811-4. 